\title{
ANALISA BESARAN RADIASI MEDAN ELEKTROMAGNETIK TV TERHADAP LINGKUNGAN KERJA
}

\section{ANALYSIS OF ELECTROMAGNETIC RADIATION TV TO WORKING ENVIRONMENT}

\author{
Johan Aristo ${ }^{1}$, Purnomosutji Dyah Prinajati ${ }^{2}$, dan Nafsan Upara ${ }^{3}$ \\ ${ }^{1}$ Teknik Lingkungan, Fakultas Teknik, Jurusan Universitas Sahid Jakarta, Jl. Prof. Dr. Soepomo, SH No.84 \\ Tebet Jakarta Indonesia, Email: aristo.johan@yahoo.co.id \\ ${ }^{2}$ Teknik Lingkungan, Fakultas Teknik, Jurusan Universitas Sahid Jakarta, Jl. Prof. Dr. Soepomo, SH No.84 \\ Tebet Jakarta Indonesia, Email: iinsoekandar@gmail.com \\ ${ }^{3}$ Jurusan Mesin, Fakultas Teknik, Universitas Pancasila, Jl. Srengseng Sawah, Jagakarsa, Jakarta Selatan 12640, \\ Indonesia, Email: uparanafsan@gmail.com
}

\begin{abstract}
ABSTRAK
Bahaya besaran dari radiasi medan elektromagnetik yang ditimbulkan melalui berbagai Jarak, tipe seperti TV Tabung, LCD TV, serta LED TV. Oleh karena itu, penelitian ini bertujuan menganalisis besaran nilai radiasi medan elektromagnetik pada setiap parameter/faktor TV (jarak, tipe pencahayaan, merk) yang berpengaruh terhadap keselamatan kesehatan kerja pada consumer hingga jasa servis TV. Jenis penelitian yang dilakukan adalah deskriptif analitik. Metode yang digunakan pada penelitian ini adalah metode Taguchi untuk mengoptimasi radiasi medan elektromagnetik pada TV 32 inchi yang paling minimum dengan parameter (faktor) kontrol jarak (10, 20, dan $30 \mathrm{~cm}$ ), Jenis Pencahayaan (Tabung, LCD, dan LED), dan Merk TV (Polytron, LG, dan Sharp) serta menggunakan Analisis Varians (ANOVA) untuk memperoleh secara kuantitatif memperkirakan kontribusi dari setiap faktor yang mempengaruhi besar Radiasi Medan Elektromagnetik. Dari hasil penelitian diperoleh besar Hasil Radiasi Medan Elektromagnetik yang minimum yaitu 32,5 Hz pada jarak (J) $30 \mathrm{~cm}$, tipe pencahayaan adalah LED, merk TV adalah Sharp. Nilai ini masih di Ambang Batas Celling sesuai Peraturan Menteri Kesehatan Republik Indonesia No. 70 Tahun 2016. Nilai parameter yang berkonstribusi terbesar pengaruhnya terhadap Radiasi Medan Elektromagnetik adalah faktor Jarak ke TV yaitu sebesar 78,44\%.
\end{abstract}

Kata Kunci: Jarak, Merk, Tipe Pencahayaan

\begin{abstract}
The magnitude of the danger of electromagnetic field radiation caused by various distances, types such as Tube TVs, LCD TVs, and LED TVs. Therefore, this study aims to analyze the magnitude of the electromagnetic field radiation values on each TV parameter / factor (distance, lighting type, brand) that affects the occupational health safety of consumers to TV service services. This type of research is analytic descriptive. The method used in this study is the Taguchi method for optimizing the electromagnetic field radiation on the 32 inch $T V$ with the minimum parameters (factor) control distance (10, 20, and $30 \mathrm{~cm}$ ), the type of lighting (tubes, LCD, and LED), and TV brands (Polytron, LG, and Sharp) and use Analysis Variance (ANOVA) to obtain quantitatively estimate the contribution of each factor that affects the magnitude of Electromagnetic Field Radiation. From the results of the study obtained a large Electromagnetic Field Radiation Results a minimum of $32.5 \mathrm{~Hz}$ at a distance (J) 30 $\mathrm{cm}$, the type of lighting is LED, the TV brand is Sharp. This value is still in the Celling Threshold in accordance with the Regulation of the Minister of Health of the Republic of Indonesia No. 70 of 2016. The parameter value which has the biggest contribution to the influence of Electromagnetic Field Radiation is the Distance to TV factor that is $78.44 \%$.
\end{abstract}

Keywords: Distance, Brand, Lighting Type 


\section{Pendahuluan}

Perkembangan Televisi pada setiap tahunnya semakin berkembang pesat. Teknologi yang digunakan pada televisi saat ini berbeda jauh dengan televisi saat pertama kali ditemukan, meskipun memiliki metode dasar yang sama. Televisi sebagai fokus dalam penelitian ini, merupakan alat media telekomunikasi dan media hiburan yang banyak digunakan yang berfungsi sebagai penerima siaran gambar bergerak beserta suara. Berdasarkan jumlah penggunaan TV sesuai Laporan tahunan oleh UC News yang berjudul "Year-end mobile content consumption trend of 2016 in Indonesia" yang dipublikasikan tanggal 17 Januari 2017 menyatakan media hiburan TV mencapai jumlah pemirsa 99,8\% dari total populasi (Rakyat Indonesia yang mempunyai televisi kurang lebih 249.987 .567 orang) dengan durasi rata-rata 1.782,5 menit setiap minggu

Perkembangan teknologi pencahayaan TV saat ini oleh beberapa merk TV antara lain Sharp, Toshiba, Samsung, Sony, LG dan lainnya dengan tipe-tipe pencahyaan Plasma, LCD dan LED mempengaruhi peningkatan pengaruhnya kepada kesehatan. Menurut Canadian Association of Optometrists (CAO) tahun 2010, duduk terlalu dekat ke TV menimbulkan tegangan dan kelelahan pada mata karena pencahayaan yang salah sehingga dapat merusak pada mata penonton. Sedangkan paparan radiasi medan listrik magnetik yang diterima penonton yang melebihi ambang batas 2 tesla dapat menyebabkan kanker. Pada kegiatan kerja di lingkungan tempat kerja seperti petugas service TV, Quality Control (QC) produksi TV, dan kegiatan bisnis persewaan game tersebut sangat dekat dengan TV dengan waktu yang lama akan menerima paparan radiasi yang cukup signifikan.

Berdasarkan hal-hal tersebut diatas, dengan perkembangan teknologi TV yang begitu cepat, Tanpa disadari dapat menimbulkan masalah kesehatan pada manusia dalam kegiatan dengan TV ini akan terpapar radiasi medan listrik magnetik secara langsung baik di rumah maupun di lingkungan tempat kerja. Sehingga dapat ditarik suatu simpulan bahwa pengaruh radiasi medan elektromagnetik terhadap kesehatan kerja masih banyak menimbulkan perdebatan dan masih diperlukan penelitian lebih lanjut.

Tujuan pada penelitian ini adalah:

a. Menganalisis nilai rata-rata radiasi medan elektromagnetik terhadap parameter TV (jarak, tipe pencahayaan, dan merk)

b. Menganalis parameter TV (jarak, tipe pencahayaan, dan merk) terhadap nilai radiasi medan elektromagnetik yang paling minimum sesuai peraturan atau standar yang berlaku

c. Menganalisis parameter TV (jarak, tipe pencahayaan, dan merk) yang berpengaruh terhadap radiasi medan elektromagnetik.

\section{Metode Penelitian}

\subsection{Jenis Penelitian}

Jenis penelitian adalah dengan menggunakan metode analisis bersifat eksprimen. Penulis melakukan pengumpulan data primer berupa survei di toko servis elektronik televisi dan data sekunder berupa data perhitungan metode taguchi, metode anova dan peraturan terkait nilai ambang batas radiasi medan elektromagnetik

\subsection{Lokasi dan Waktu Penelitian}

Tempat untuk melakukan pengujian untuk penelitian ini adalah di Toko service elektronik TV. Waktu pelaksanaan penelitian pada bulan 18 Desember 2017 sampai dengan 17 Januari 2018. 


\subsection{Studi Lapangan}

Studi lapangan dilakukan untuk mengetahui kondisi actual dilapangan terhadap besar radiasi yang dikeluarkan oleh televisi. Dari studi lapangan diperoleh data sebagai berikut:

a. Ukuran TV yang banyak di services

b. Jarak aman menonton

c. Besaran Radiasi

\subsection{Jumlah Eksperimen}

Menggunakan metode matriks Ortogonal dalam menetapkan jumlah eksperimen, Derajat kebebasan $=$ Jumlah faktor $\mathrm{x}$ (jumlah level -1 )

$$
=3 \times(3-1)=6 \text { derajat kebebasan }
$$

Matriks Ortogonal yang dipilih adalah L9 $\left(3^{4}\right)$, dimana:

$\mathrm{L}=$ rancangan bujursangkar latin

$9=$ banyaknya eksperimen

$3=$ banyaknya level

$4=$ banyak faktor

Maka derajat kebebasan $=4 \times(3-1)=8$ derajat kebebasan

Jumlah eksperimen yang dipilih adalah $\mathrm{L} 9=9$ spesimen. Hal ini dibutuhkan agar ketelitian dalam penelitian dan perhitungan lebih baik dalam mendapatkan hasil yang maksimal.

\subsection{Konsep Penelitian dan Input Parameter Proses}

Konsep peneltian dari setiap input parameter proses dapat dilihat seperti pada Tabel 1 , sedangkan rancangan eksperimen terdapat pada Tabel 2

Tabel 1 Faktor dan Level

\begin{tabular}{cccccc}
\hline \multicolumn{3}{c}{ Parameter } & \multicolumn{5}{c}{ Level } \\
\hline Faktor & Simbol & Satuan & 1 & 2 & 3 \\
Jarak & $\mathrm{J}$ & Meter & $\mathrm{J} 1$ & $\mathrm{~J} 2$ & $\mathrm{~J} 3$ \\
$\begin{array}{c}\text { Tipe } \\
\text { Pencahayaan }\end{array}$ & $\mathrm{T}$ & - & $\mathrm{T} 1$ & $\mathrm{~T} 2$ & $\mathrm{~T} 3$ \\
$\begin{array}{c}\text { Merk TV } \\
\text { Ter }\end{array}$ & $\mathrm{M}$ & - & $\mathrm{M} 1$ & $\mathrm{M} 2$ & $\mathrm{M} 3$ \\
\hline
\end{tabular}

Tabel 2 Rancangan Ortogonal Aray Eksperimen

\begin{tabular}{ccccc}
\hline Eksperimen & $J$ & $T$ & $M$ & $\begin{array}{c}\text { Besar } \\
\text { Radiasi }\end{array}$ \\
\hline 1 & 1 & 1 & 1 & \\
2 & 1 & 2 & 2 & \\
3 & 1 & 3 & 3 & \\
4 & 2 & 1 & 2 & \\
5 & 2 & 2 & 3 & \\
6 & 2 & 3 & 1 & \\
7 & 3 & 1 & 3 & \\
8 & 3 & 2 & 1 & \\
9 & 3 & 3 & 2 & \\
\hline
\end{tabular}




\section{Hasil Penelitian Dan Pembahasan}

\subsection{Perhitungan dan Pembahasan dengan Metode Taguchi}

Pengukuran mengikuti metode Taguchi dimulai dari parameter proses yaitu dalam eksperimen ini menggunakan 3 faktor kontrol dengan 3 level sebagaimana diperlihatkan pada Tabel 3.

Tabel 3 Faktor dan Level Eksperimen

\begin{tabular}{lccccc}
\hline Faktor & \multirow{2}{*}{ Kode } & \multirow{2}{*}{ Satuan } & \multicolumn{3}{c}{ Level } \\
\cline { 4 - 6 } & kontrol) & & 1 & 2 & 3 \\
\hline Jarak & $\mathrm{J}$ & $\mathrm{cm}$ & $\mathrm{J} 1$ & $\mathrm{~J} 2$ & $\mathrm{~J} 3$ \\
Tipe & $\mathrm{T}$ & - & $\mathrm{T} 1$ & $\mathrm{~T} 2$ & $\mathrm{~T}$ \\
Pencahayaan & & & & 3 \\
Merk & $\mathrm{M}$ & - & $\mathrm{M}$ & $\mathrm{M} 2$ & $\mathrm{M}$ \\
& & & 1 & & 3 \\
\hline
\end{tabular}

Keterangan:

$\mathrm{J} 1=10 \mathrm{~cm} ; \quad \mathrm{J} 2=20 \mathrm{~cm} ; \mathrm{J} 3=30 \mathrm{~cm}$

T1 = TV Tabung; T2 = LCD ; T3 = LED

M1 = Polytron ; $\quad$ M2 = LG ; M3 = Sharp

Semua TV ukuran sama yaitu 32 inchi.

Berdasarkan hasil eksperimen matriks Ortogonal aray yang terdapat pada Tabel 2, sebagaimana telah diperlihatkan pada Tabel 4.

Tabel 4 Hasil Pengukuran Radiasi Medan Elektromagnetik (ME)

\begin{tabular}{ccccc}
\hline $\begin{array}{c}\text { No. } \\
\text { Eksperimen }\end{array}$ & $J$ & $T$ & $M$ & $R(\mathrm{~Hz})$ \\
\hline 1 & 1 & 1 & 1 & 964 \\
2 & 1 & 2 & 2 & 641 \\
3 & 1 & 3 & 3 & 572 \\
4 & 2 & 1 & 2 & 496 \\
5 & 2 & 2 & 3 & 324 \\
6 & 2 & 3 & 1 & 289 \\
7 & 3 & 1 & 3 & 277 \\
8 & 3 & 2 & 1 & 141 \\
9 & 3 & 3 & 2 & 86 \\
\hline
\end{tabular}

Kemudian pada Tabel 4 hasil pengukuran radiasi medan elektromagnetik dilakukan pengolahan data. Hasil pengolahan data radiasi medan elektromagnetik terdapat pada Tabel 5

Tabel 5 Tabel respon dari pengaruh faktor untuk Radiasi Medan Elektromagnetik

\begin{tabular}{lccc} 
& $\boldsymbol{J}$ & $\boldsymbol{T}$ & $\boldsymbol{M}$ \\
\hline Level 1 & 725,7 & 579,0 & 464,7 \\
Level 2 & 369,7 & 368,7 & 407,7 \\
Level 3 & 168,0 & 315,7 & 391,0 \\
Selisih & 557,7 & 263,3 & 73,7 \\
Rangking & 1 & 2 & 3 \\
\hline
\end{tabular}

Kondisi optimal Radiasi Medan Elektromagnetik terkecil adalah pada J3 $=(168,0), \mathrm{T} 3=$ $(315,7)$, dan $\mathrm{M} 3=(391,0)$, sedangkan terbesar adalah pada $\mathrm{J} 1=(725,7), \mathrm{T} 1=(579,0)$, dan $\mathrm{M} 1$ 
$=(464,7)$, Respon dari pengaruh faktor utama rata rata Radiasi Medan Elektromagnetik terdapat pada Grafik 1.

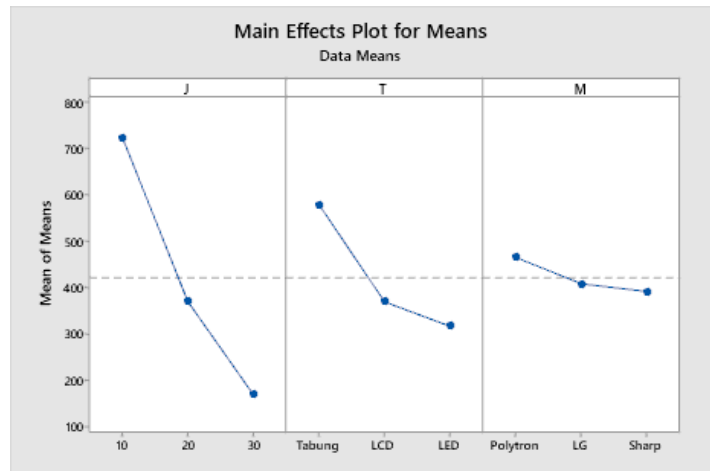

Grafik 1. Grafik respon dari pengaruh faktor utama rata rata Radiasi Medan Elektromagnetik

Untuk mencari faktor yang berpengaruh pada variasi karakteristik kualitas dimana S/N untuk karakter kualitas semakin kecil, semakin baik (small-the-best) untuk Radiasi Medan Elektromagnetik, dihitung dengan rumus dan didasarkan Tabel 4.2, Berikut dibawah ini adalah Tabel Rasio S/N dan grafik berdasarkan hasil perhitungan Radiasi Medan Elektromagnetik dengan perhitungan rasio S/N terdapat pada Tabel 6 .

Tabel 6Tabel Rasio S/N untuk Radiasi Medan Elektromagnetik

\begin{tabular}{cccccc}
\hline No. Eksperimen & $J$ & $T$ & $M$ & $R(\mathrm{~Hz})$ & Rasio S/N Untuk $R$ \\
\hline 1 & 1 & 1 & 1 & 964 & $-59,68$ \\
2 & 1 & 2 & 2 & 641 & $-56,14$ \\
3 & 1 & 3 & 3 & 572 & $-55,15$ \\
4 & 2 & 1 & 2 & 74 & $-53,90$ \\
5 & 2 & 2 & 3 & 31 & $-50,21$ \\
6 & 2 & 3 & 1 & 8 & $-49,21$ \\
7 & 3 & 1 & 3 & 0 & $-48,85$ \\
8 & 3 & 2 & 1 & 0 & $-42,98$ \\
9 & 3 & 3 & 2 & 0 & $-38,69$ \\
\hline
\end{tabular}

Kemudian pada Tabel 6 hasil perhitungan rasio S/N radiasi medan elektromagnetik dilakukan pengolahan data. Hasil pengolahan data rasio $\mathrm{S} / \mathrm{N}$ radiasi medan elektromagnetik terdapat pada Tabel 7

Tabel 7 Tabel Pengaruh Utama rata-rata Rasio S/N terhadap Radiasi Medan Elektromagnetik

\begin{tabular}{lccc} 
& $\boldsymbol{J}$ & $\boldsymbol{T}$ & $\boldsymbol{M}$ \\
\hline Level 1 & $-56,99$ & $-54,15$ & $-50,63$ \\
Level 2 & $-51,11$ & $-49,78$ & $-49,58$ \\
Level 3 & $-43,51$ & $-47,69$ & $-51,40$ \\
Selisih & 13,48 & 6,46 & 1,82 \\
Rangking & 1 & 2 & 3 \\
\hline
\end{tabular}


Tabel 7 terlihat bahwa kondisi optimal Radiasi Medan Elektromagnetik terkecil adalah pada $\mathrm{J} 1=(-56,99), \mathrm{T} 1=(-54,15)$ dan $\mathrm{M} 3=(-51,40)$. Respon dari pengaruh faktor utama rata rata Radiasi Medan Elektromagnetik terdapat pada Grafik 2.

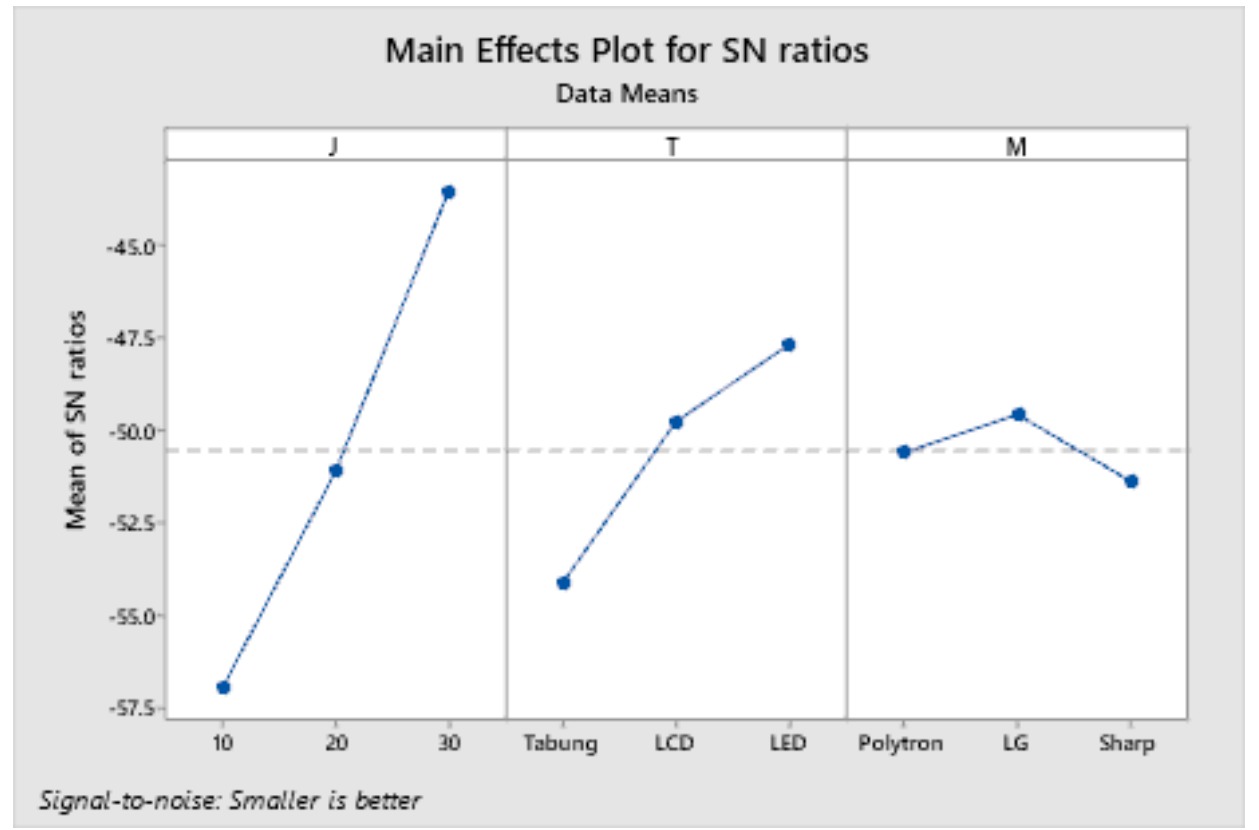

Grafik 2 Grafik pengaruh utama Untuk data rata rata Rasio S/N faktor terhadap Radiasi Medan Elektromagnetik

Grafik 2 terlihat bahwa kondisi optimal Radiasi Medan Elektromagnetik terkecil adalah pada $\mathrm{J} 1=(-56,99), \mathrm{T} 1=(-54,15)$ dan $\mathrm{M} 3=(-51,40)$.

Nilai optimal radiasi Medan Elektromagnetik diperlihatkan pada Tabel 8.

Tabel 8 Tabel Nilai optimal radiasi Medan Elektromagnetik

\begin{tabular}{cccc}
\hline Faktor & Parameter Optimal & Nilai & Optimal \\
\hline $\begin{array}{c}\text { Radiasi Medan } \\
\text { Elektromagnetik }(R)\end{array}$ & Rata-rata $: \mathrm{J} 3=(168,0), \mathrm{T} 3=(315,7)$, dan $\mathrm{M} 3=(391,0)$ & $32,5 \mathrm{~Hz}$ & Kecil \\
\cline { 2 - 3 } & $\mathrm{S} / \mathrm{N}: \mathrm{J} 1=(-56,99), \mathrm{T} 1=(-54,15)$ dan $\mathrm{M} 3=(-51,40)$ & $-61,48 \mathrm{~Hz}$ & \\
\hline
\end{tabular}

Dari Tabel 8 terlihat bahwa Radiasi Medan Elektromagnetik terkecil sebesar 32,5 Hz terdapat pada Jarak $30 \mathrm{~cm}$ untuk tipe pencahayaan LED dan Merk TV Sharp. Untuk Signal to Noise (S/N) Radiasi Medan Elektromagnetik terkecil sebesar $-61,48 \mathrm{~Hz}$ terdapat pada Jarak $10 \mathrm{~cm}$ untuk tipe pencahayaan Tabung dan Merk TV Sharp.

\subsection{Perhitungan dan Pembahasan dengan Metode ANOVA}

Analisis varian (ANOVA) adalah suatu metode statistik untuk menginterprestasikan data - data hasil eksperimen yaitu teknik perhitungan yang memungkinkan secara kuantitatif memperkirakan kontribusi dari setiap faktor pada semua pengukuran. Analisis Varian dilkukan dengan menggunakan software Minitab 19. Dari hasil perhitungan diperoleh kontribusi tiap faktor yaitu Jarak (J), Tipe Pencahayaan (T), dan Merk TV (M) diperlihatkan pada Tabel 9. 
Tabel 9 Tabel ANOVA untuk Radiasi Medan Elektromagnetik Rata-Rata

Analysis of Variance for Means

\begin{tabular}{lcccccc}
\hline Source & DF & Seq SS & Adj SS & Adj MS & F & P \\
\hline $\mathrm{J}(\mathrm{cm})$ & 2 & 478398 & 478398 & 239199 & 78,12 & 0,013 \\
$\mathrm{~T}$ & 2 & 116394 & 116394 & 58197 & 19,01 & 0,050 \\
$\mathrm{M}$ & 2 & 8954 & 8954 & 4477 & 1,46 & 0,406 \\
Residual Error & 2 & 6124 & 6124 & 3062 & & \\
\hline Total & 8 & 609869 & & & & \\
\hline
\end{tabular}

Sumber: Hasil perhitungan dengan software Minitab 19

Berdasarkan perhitungan presentase konstribusi dengan menggunakan metode ANOVA pada tiap faktor J, T, dan M terhadap besar Radiasi Medan Elektromagnetik pada Jarak = $78,44 \%$, Tipe Pencahayaan $=19,08 \%$, Merk $=1,47 \%$.

\section{Kesimpulan Dan Saran}

Dari hasil pengolahan data dan analisis di Bab 4 terhadap besaran Radiasi Medan Elektromagnetik, maka didapatkan dibuat kesimpulan:

a. Nilai rata-rata radiasi medan elektromagnetik terhadap parameter TV (jarak, tipe pencahayaan, dan Merk) yaitu $\bar{Y}=421,1 \mathrm{~Hz}$.

b. Parameter radiasi medan elektromagnetik yang minimum terhadap lingkungan kerja di Toko Servis Jakarta pada ukuran TV 32" yaitu sebesar 32,5 Hz pada parameter Kontrol yaitu Jarak $(\mathrm{J})=30 \mathrm{~cm}$, jenis pencahayaan adalah LED dan Merk TV adalah Sharp. Nilai Radiasi Medan Elektromagnetik ini masih berada didalam Nilai Ambang Batas (NAB) Celing sebesar 25 kV/m sesuai Peraturan Menteri Kesehatan Republik Indonesia No. 70 Tahun 2016 sehingga dinyatakan Aman.

c. Parameter yang mempunyai pengaruh terbesar terhadap nilai radiasi medan elektromagnetik adalah Jarak (J) dari TV ke teknisi services yaitu sebesar 78,44\%.

d. Untuk jarak aman melihat TV 32 inchi pada merk Sharp LED adalah $30 \mathrm{~cm}$ dengan nilai radiasi sebesar $32,5 \mathrm{~Hz}$, sehingga setiap kegiatan TV harus berada pada jarak minimum 30 $\mathrm{cm}$.

e. Untuk penelitian lebih lanjut, disarankan ukuran TV yang lebih dari 32" dan dengan tipe pencahayaan sesuai teknologi terkini. 


\section{Daftar Pustaka}

Alit Swamardika, I.B. (2009). Pengaruh Radiasi Gelombang Elektromagnetik Terhadap Kesehatan Manusia (Suatu Kajian Pustaka), Jurnal Teknologi Elektro Vol.8 No.1 Januari-Juni 2009

Canadian Association of Optometrist (CAO). (2010). Work Life Balance. Royal Center Vancouver: Canadian Association of Optometrist

Nikki. (2010). Radiasi Elektromagnetik. Jakarta: Diakses pada 25 Januari 2013 pada pukul 08.26 WIB

Peraturan Menteri Kesehatan Republik Indonesia Nomor 70 Tahun 2016 Tentang Standar Dan Persyaratan Kesehatan Lingkungan Kerja Industri

Ritonga, Habib. (2012). Penyakit Akibat Kelamaan Nonton TV. Jakarta: Kompas.com diunduh tanggal 15 Juni 2017

Soejanto, Irwan. (2009). Desain Eksperimen Metode Taguchi. Yogyakarta: Edisi pertama Graha Ilmu 